\section{Antibacterial Susceptibility Pattern of the Pseudomonas aeruginosa and Staphylococcus aureus after Exposure to Electromagnetic Waves Emitted from Mobile Phone Simulator}

\author{
Movahedi M. M..$^{1,2}$, Nouri F.3, Tavakoli Golpaygani A.4, \\ Ataee L. ${ }^{5}$, Amani S.5, Taheri M. ${ }^{6 * \text { () }}$
}

\begin{abstract}
Background: The increasing use of telecommunication devices such as Wi-Fi modems and mobile phones in the recent years can change the cellular structure of microorganisms so the generation of electromagnetic waves has led to concern in the community whenever be exposed to these fields and may have harmful effects on human health.

Material and Methods: In this experimental study, standard strains of bacteria were prepared on Mueller-Hinton agar for bacterial growth to obtain 0.5 McFarland turbidity $\left(1.5 \times 10^{8} \mathrm{CFU}\right)$ of bacteria. Antibiotic susceptibility test using the Kirby-Bauer disk diffusion method was done. For Staphylococcus aureus and Pseudomonas aeruginosa, antibiotics susceptibility test was conducted. The test group was exposed to electromagnetic waves emitted by mobile phone simulator with a frequency of $900 \mathrm{MHz}$ and the control group were not exposed.

Results: The results revealed that increasing duration of exposure to electromagnetic waves emitted by the mobile simulators with a frequency of $900 \mathrm{MHz}$ especially after $24 \mathrm{~h}$ of exposure, can increase bacterial resistance in $S$. aureus, and $P$. aeruginosa.
\end{abstract}

Conclusion: Several factors can cause bacterial resistance against antibiotics. One of these factors is the electromagnetic waves emitted from mobile simulator with a frequency of $900 \mathrm{MHz}$, which can increase the permeability of the cell wall of bacteria.

Citation: Movahedi M. M, Nouri F, Tavakoli Golpaygani A, Ataee L, Amani S, Taheri M. Antibacterial Susceptibility Pattern of the Pseudomonas aeruginosa and Staphylococcus aureus after Exposure to Electromagnetic Waves Emitted from Mobile Phone Simulator. J Biomed Phys monas aeruginosa and Staphylococcus aureus after Exposure to

\section{Keywords}

Microbial Sensitivity Tests, Electromagnetic waves, Mobile simulator, Pseudomonas aeruginosa, Staphylococcus aureus

\section{Introduction}

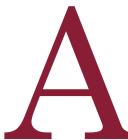
ntibiotic resistance is considered to be a major problem in the treatment and control of the infection. In recent years, bacterial resistance has become widespread to common antibiotics worldwide, so that the use of antimicrobials with this resistance pattern has been considered as a major problem in the medical community. In addition, since the detection of this resistance pattern due to their rapid spreads, an abundance of the antibiotic resistance across the universe
${ }^{1} \mathrm{PhD}$, Department of Medical Physics and Biomedical Engineering, School of Medicine, Shiraz University of Medical Sciences, Shiraz, Iran

${ }^{2} \mathrm{PhD}$, lonizing and Non-Ionizing Radiation

Protection Research

Center (INIRPRC), Shiraz

University of Medical Sci-

ences, Shiraz, Iran

${ }^{3}$ PhD, Department of

Pharmaceutical Biotech-

nology, School of Phar-

macy, Hamadan Univer-

sity of Medical Sciences,

Hamadan, Iran

${ }^{4} \mathrm{MD}$, Department of

Biomedical Engineer-

ing, Standard Research

Institute, Karaj, Iran

${ }^{5} \mathrm{PhD}$,Shiraz University

of Medical Sciences,

Shiraz, Iran

${ }^{6} \mathrm{PhD}$,Department of

Medical Microbiology,

Faculty of Medicine,

Hamadan University

of Medical Sciences,

Hamadan, Iran

*Corresponding author: M. Taheri

Medical Microbiology,

Hamadan University

of Medical Sciences

Hamadan, Iran

E-mail: motaheri360@ gmail.com

Received: 9 January 2019 Accepted: 25 January 2019 
has been observed. This can often occur due to the unnecessary consumption of antibiotics. On the other hand, patients' specific conditions, long-term hospitalization, immunodeficiency and extensive use of immunosuppressive drugs and aggressive therapies (such as a catheter, intravascular shunt, and endotracheal tube), and other factors increase the drug resistance in different parts of the hospitals [1]. Therefore, the optimal applying and appropriate therapeutic strategies in order to control the infection and reducing the prevalence of antibiotic-resistant organisms is necessary [2]. $P$. aeruginosa is a hospital pathogen that causes infectious wounds and burns, and opportunistic diseases such as meningitis, urinary tract infection [3], respiratory system involvement [4], otitis media in swimmers [5], eye infections, and sepsis in infants or people with disabilities [6], especially in people with immune system deficiencies [7]. Also, S. aureus is a major pathogen, which is found everywhere, especially in infant ward, ICUs, surgery rooms and chemotherapy departments [8,9], and will lead to various types of infections such as food poisoning or life-threatening infections [10] caused by direct infection of the wound, such as Staphylococcus wound infection [11] after surgery or infection following trauma $[10,12]$.

On the other hand, in recent years, the use of electromagnetic sources and telecommunication devices such as mobile phones have increased, and concerns have been raised for people in the community who are exposed to these fields, whose effects on the human health are under investigation [13-15]. Various classifications regarding the types of effects of waves on the human body have been made. In one classification, the effects of waves are divided into two categories. The first group has a reversible effect, such as the heat that increases its temperature, but after cooling, the nature of it remains preserved [16]. The second group, the irreversible effect, such as heat on the egg, increases the temperature and changes its nature, and does not return to the first state after cooling down [17].

In another classification, these damages are divided into thermal and non-thermal [18]. thermal damage means raising the temperature of cells and tissues without triggering temperature-sensitive receptors on the skin surface. Due to increased temperature in the tissues, chemical changes occur in the cells, which may lead to various disorders and illnesses. For example, due to increased body temperature, changes in enzymatic processes and cytokine levels [19], disturbances in calcium metabolism, and changes in growth and cell proliferation will occur [18]. Until recently, only thermal damages were considered and unhealthy electromagnetic waves were unaware [20]. Unhealthy damage causes permanent changes in the structure of the cell. Because of unhealthy damage due to the heat and the intensity of the wave, these damages may also be caused by the weakest wave. Some of these damages including altering blood chemistry such as reducing red blood cells, affecting the reproductive system, causing cancer, nervous disorders, increased irritability, headache, dizziness, nausea, eye irritation, and feeling of a foreign body in the eye. Mobile waves, with similar effects on the body, can cause discomfort and diseases such as cataracts [21]. The third-generation 3G (a new version of mobile phone technology) is an important wireless communication device that meets the needs of modern societies and is rapidly increasing worldwide. $3 \mathrm{G}$ mobile phones run on radiofrequency of 900-1800 MHz [22, 23].

Nowadays, exposure to electromagnetic waves is unavoidable; as a result, many home appliances such as a hairdryer and washing machine produce harmful electromagnetic waves whose intensity can be as strong as waves of the electromagnetic emissions released below the high-pressure electric shock welder [24]. According to the reports, every healthy person is exposed to 361 million roentgen radiation [25]. Therefore, we should be aware of the safety and protection issues against the unde- 
sirable effects of electromagnetic waves [26]. In order to obtain a more accurate understanding of the effects of electromagnetic waves, the present study examined the effect of shortterm exposure to electromagnetic waves emitted from mobile phone simulator with a frequency of $900 \mathrm{MHz}$ as a mechanism of stress, on the sensitivity of pathogenic microorganisms, $P$. aeruginosa and $S$. aureus against multiple antibiotics.

\section{Material and Methods}

\section{Materials}

Materials used in this experimental study, include Muller Hinton Agar and nutrient broth culture media, $P$. aeroginosa (ATCC No. 27853), S. aureus bacteria (ATCC No. 25923), antimicrobial discs (ROSCO, Denmark) (Table 1). The equipment used in this research include Digital balance A \& D Model 120, (Japan), $37{ }^{\circ} \mathrm{C}$ incubator (Behdad, Iran), UV/Vis Spectrophotometer 2100 (UNICO, America), RF Simulator (simulated mobile source with wave production of $900 \mathrm{MHz}$ ).

Table 1: Antimicrobial agents used in the present study.

\begin{tabular}{ccc} 
Antimicrobials & Abbreviation & $\begin{array}{c}\text { Potency } \\
(\boldsymbol{\mu} \mathbf{g})\end{array}$ \\
\hline Piperacillin & PIPRA & 100 \\
\hline Cefotaxime & CTX & 30 \\
\hline Ceftriaxone & CTR & 30 \\
\hline Amikacin & AMI & 40 \\
\hline Imipenem & IMI & 10 \\
\hline Aztreonam & AZT & 30 \\
\hline Trimethoprim-Sul- & SXT & 25 \\
famethoxazole & & 10 \\
\hline Tetracycline & TET & 5 \\
\hline Vancomycin & VANCO & 5 \\
\hline Ciprofloxacin & CIPR & 5
\end{tabular}

Preparation of culture media

At the first step, a specific amount of each medium powder was dissolved in distilled water according to Manufacturer's instructions. After that, sterile Muller Hinton Agar media was dispersed in the microbiological plates.

Bacterial culture and antimicrobial susceptibility test

$P$. aeruginosa and $S$. aureus bacteria inoculated in the nutrient broth medium separately and incubated at $37^{\circ} \mathrm{C}$. Bacterial density was measured every $20 \mathrm{~min}$ using UV/Vis spectrophotometer at an optical density of $625 \mathrm{~nm}$. When the bacterial concentration reached up to standard 0.5 McFarland, the fresh culture of each suspension was taken on, by the Muller Hinton Agar plates using sterile swabs. In order to examine the antibacterial susceptibility of the used microorganism, the antimicrobial discs were put on the Muller Hinton agar plates containing bacteria. Then these plates were classified as control (unexposed) and test or exposed group which were exposed to 900 $\mathrm{MHz}$ radiofrequency radiation emitted by mobile phone simulator for $2,4,6,8,10$ and 24 $\mathrm{h}$ and incubated for $18 \mathrm{~h}$ at $37^{\circ} \mathrm{C}$. Finally, the average inhibition zone of each antimicrobial disc was recorded and compared with the control group.

\section{Statistical Analysis}

Each experiment was carried out in triplicate to minimize the variations. Data reported as mean $\pm \mathrm{SD}$ and data comparison was done using non-parametric Mann-Whitney test.

\section{Results}

The results of electromagnetic radiation from mobile simulator on $P$. aeruginosa

Inhibition zone diameter of $P$. aeruginosa bacteria after 2, 4, 6, 8, 10 and 24 h exposure to $900 \mathrm{MHz}$ for each antibiotic was examined. As shown in Figure 1, for CTX after 2 and 4 
$\mathrm{h}$, for CTX and LEVO after $6 \mathrm{~h}$, for CIPR, LEVO and IMI after $8 \mathrm{~h}$, for CIPR and IMI after $10 \mathrm{~h}$ and finally for AMI, CIPR, CTX, PIPRA and LEVO after $24 \mathrm{~h}$ (Figure 2) bacterial exposure to $900 \mathrm{MHz}$ radiofrequency radiation, antimicrobial susceptibility against $P$. aeruginosa decreased, hence the antibacterial resistance enhanced. In all measurements, statistical analysis revealed that all aforementioned changes were significant ( $\mathrm{p}$-value $\leq$ $0.05)$.

The results of electromagnetic radiation from mobile simulator on S. aureus

Inhibition zone diameter in $S$. aureus bacte-

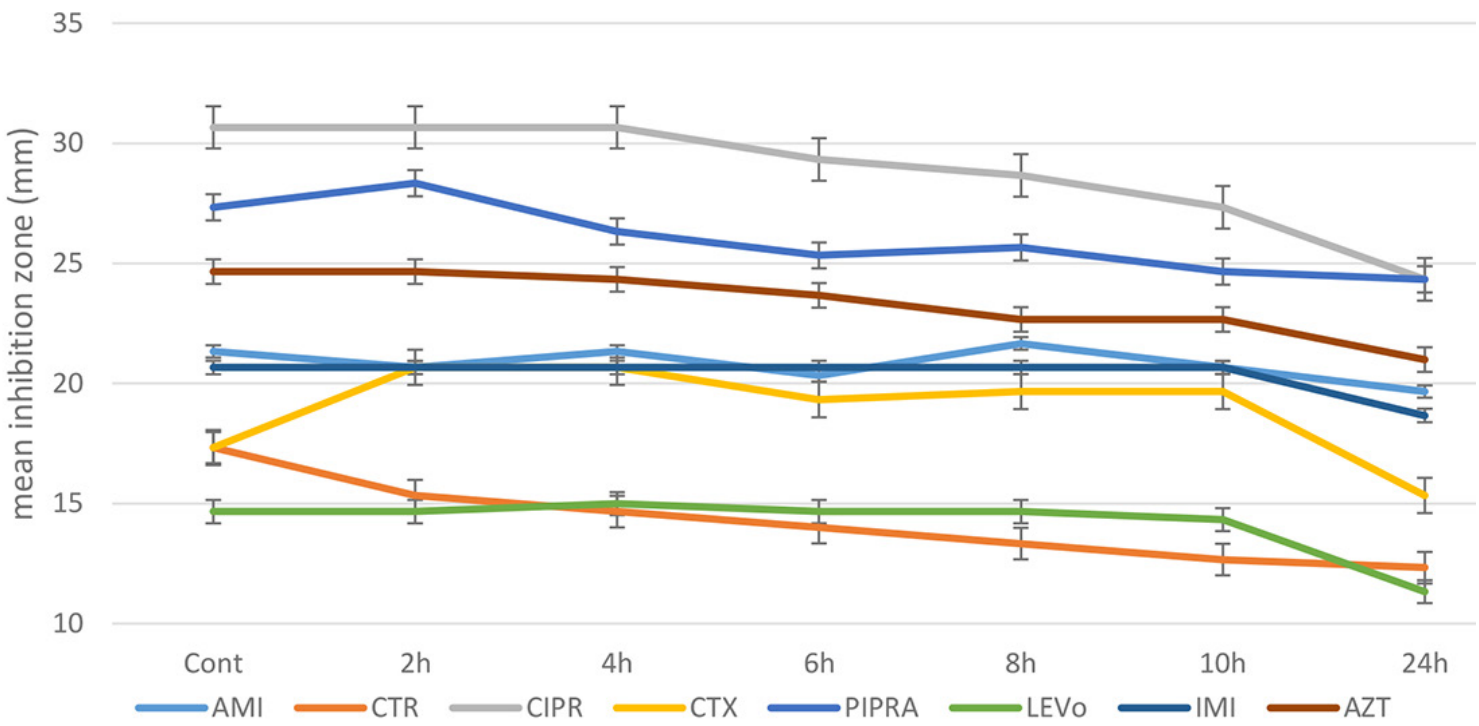

Figure 1: Mean inhibition zone diameter in Pseudomonas aeruginosa against various antibiotics during 24 hours.

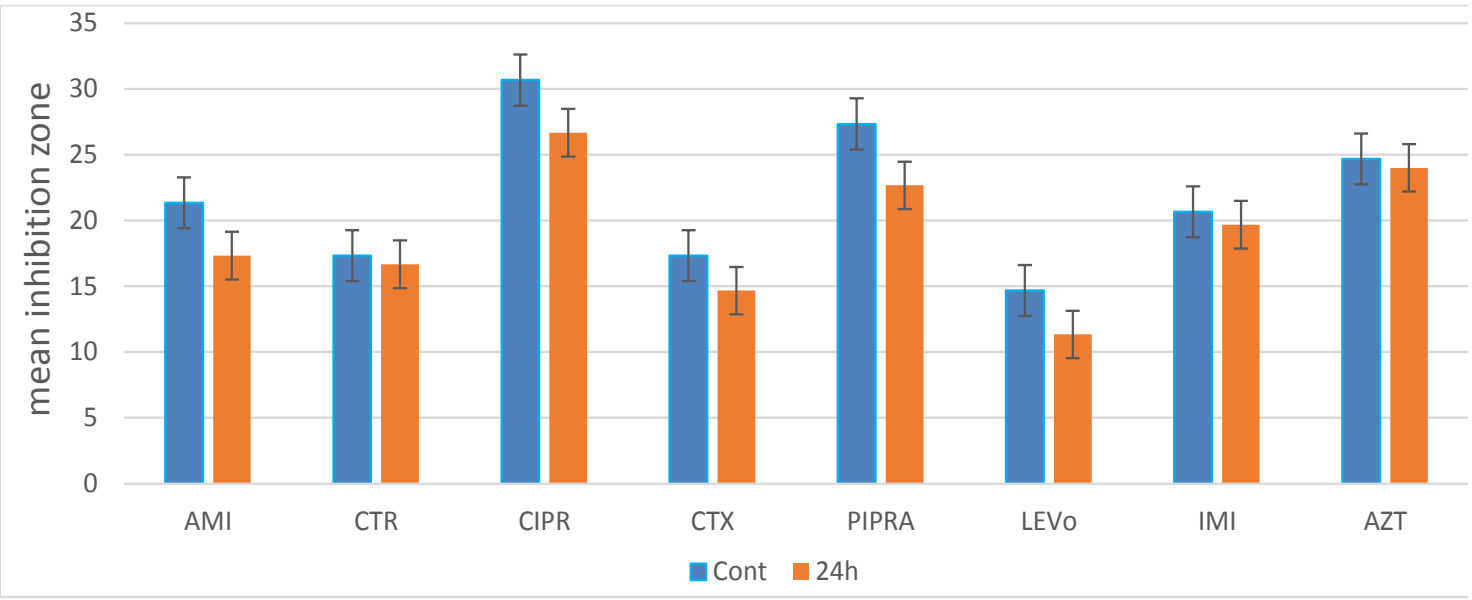

Figure 2: Mean inhibition zone diameter in Pseudomonas aeruginosa against various antibiotics in $24 \mathrm{hr}$ exposure. 
ria after $2,4,6,8,10$ and $24 \mathrm{~h}$ exposure to 900 $\mathrm{MHz}$ emitted from a mobile simulator for each antibiotic was examined. After $2 \mathrm{~h}$ for CTR and VANCO, after 4 and $6 \mathrm{~h}$ for CTR, AMI, and TET, after $8 \mathrm{~h}$ for CTR, LEVO, AMI, TET, SXT and AMP, and after $10 \mathrm{~h}$ for CTR, LEVO, AMI, TET, SXT and after $24 \mathrm{~h}$ exposure for LEVO, AMI, TET, SXT, AMP, and PIPRA were decreased in comparison with the non-exposed group. All of these differences were statistically significant $(p<0.05)$. The results of the mean inhibition zone measurements in $S$. aureus were plotted in Figure 3. According to this chart, $S$. aureus bacteria had different changes in the response to antimicrobial discs at different times.

The effect of mobile simulator radiation with a frequency of $900 \mathrm{MHz}$ on S. aureus bacteria, revealed that after $8 \mathrm{~h}$ exposure bacteria tend to be resistant against used antimicrobial agents. This change is more remarkable in amikacin and tetracycline, although all agents in the bacteria encountered a mobile simulator after $8 \mathrm{~h}$ exhibit resistance (Figure 4 ).

In addition, the effect of the mobile simulator on the $S$. aureus bacteria was the most resistant to the group of sham after $24 \mathrm{~h}$ of radiation in the antibiotic of levofloxacin and increased sensitivity in the antibiotics of piperacillin and ampicillin. However, significant changes were observed in all antibiotics (Figure 5).

\section{Discussion}

The purpose of this study was to investigate the effect of short-term exposure to radiofrequency radiation from mobile phone simulator on the susceptibility of pathogenic microorganisms $P$. aeruginosa and $S$. aureus against multiple antibiotics. The results of this study showed that exposure to $900 \mathrm{MHz}$ emitted from the mobile simulator for bacterial strains of $S$. aureus and $P$. aeruginosa during $24 \mathrm{~h}$ caused significant changes in structural properties and resistance to the antibiotics studied. So that $P$. aeruginosa bacteria were resistant to all antibiotics after $24 \mathrm{~h}$ of irradiation compared to the non-exposed (control) group, and $S$. aureus bacteria were resistant to some antibiotics such as LEVO, TET, and SXT, after $24 \mathrm{~h}$ of radiation compared with the control

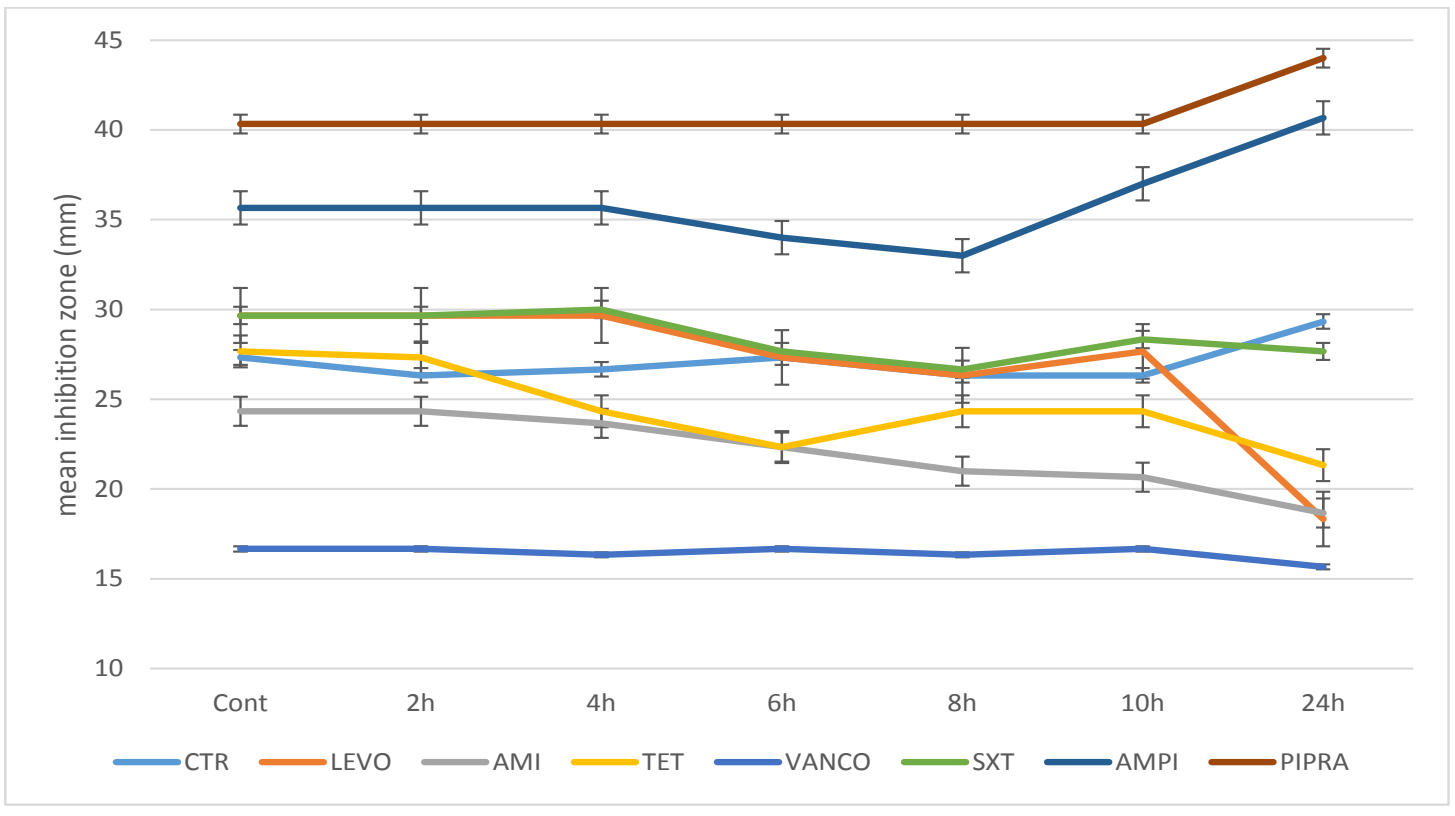

Figure 3: Mean inhibition zone diameter in Staphylococcus aureus against various antibiotics during 24 hours. 


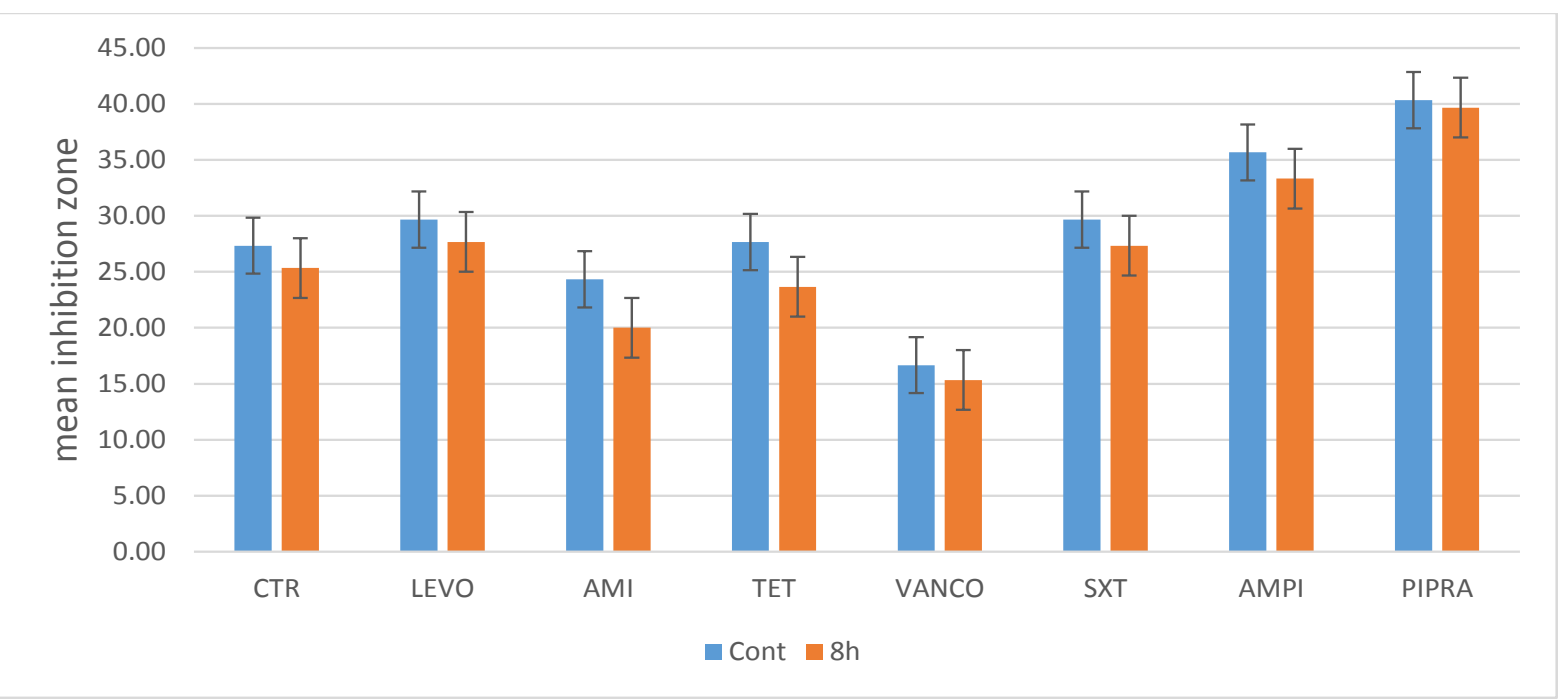

Figure 4: Mean inhibition zone diameter in Staphylococcus aureus against various antibiotics in $8 \mathrm{hr}$ exposure.

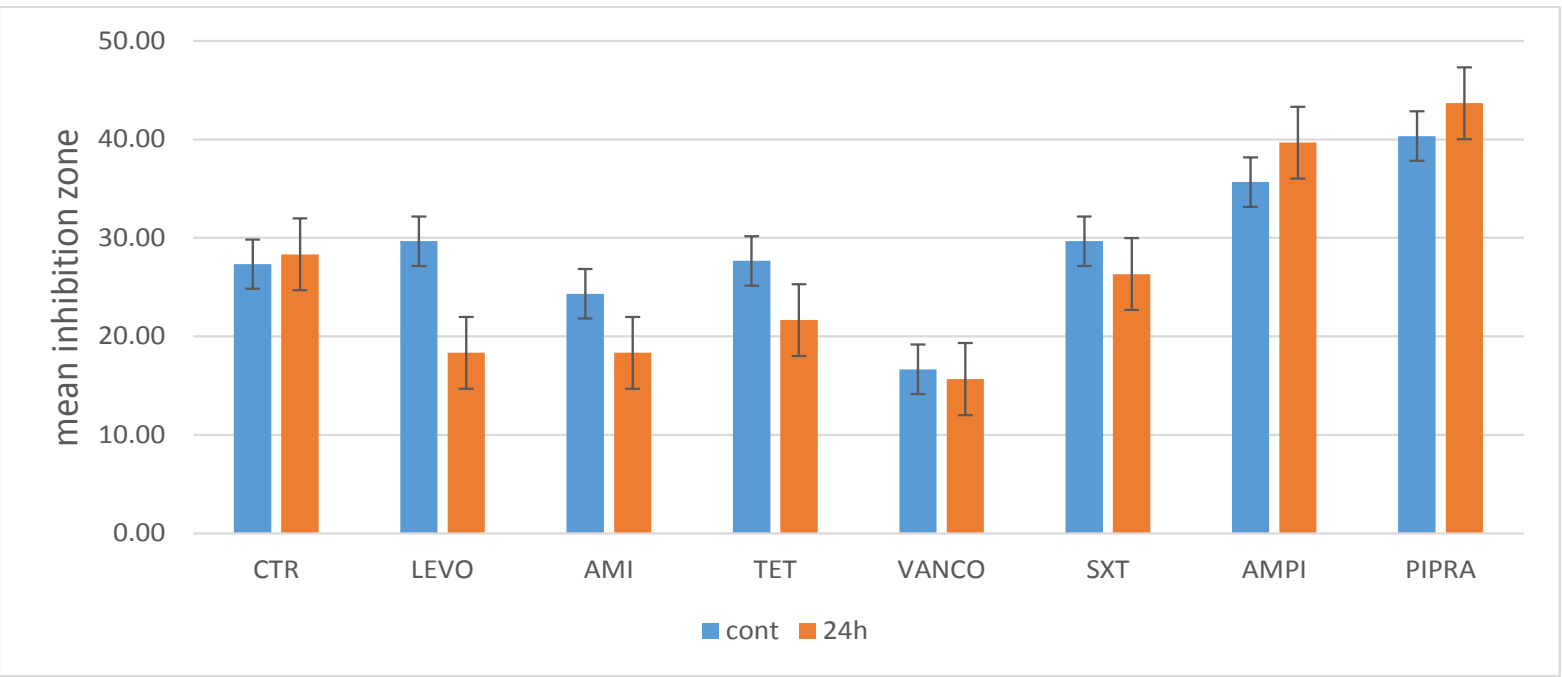

Figure 5: Mean inhibition zone diameter in Staphylococcus aureus against various antibiotics in $24 \mathrm{hr}$ exposure.

group and to the antibiotics of PIPRA, AMPI, and CTR were susceptible.

In a study, Mortazavi et al. showed antimicrobial susceptibility of Klebsiella spp., $S$. aureus and streptococci (group A), were investigated bacteria after exposure to $7-13.5$ $\mathrm{MHz}$ diagnostic ultrasound probes for $5 \mathrm{~min}-$ utes. For $S$. aureus bacteria, vancomycin, er- ythomycin and amoxicillin antibiotics and for streptococci and Klebsiella spp. nitrofurantoin, nalidixic acid, and gentamicin antibiotics were used. The results showed that $S$. aureus was resistant to erythomycin and sensitive to vancomycin [27]. In this study, ultrasound waves altered the antimicrobial susceptibility in staphylococcus bacteria that is inconsistent 
with the present study findings.

In 2017, Taheri et al. reported the Escherichia coli and Listeria monocytogenes after 3, 6, 9, 18 and $24 \mathrm{~h}$ of radiation emitted by Wi-Fi modems with the frequency of 2.4 $\mathrm{GHz}$ and mobile simulator with a frequency of $900 \mathrm{MHz}$ showed different responses. In this study, the antibiotics of piperacillin, levofloxacin, aztreonam, ciprofloxacin, and cefotaxime were used. After $9 \mathrm{~h}$ exposure to $\mathrm{Wi}-$ Fi frequencies, the bacteria were resistant to ciprofloxacin antibiotic and were susceptible to ceftriaxone, cefotaxime and levofloxacin antibiotics [28]. However, in our study $S$. aureus bacteria were resistant to the antibiotics of levofloxacin and TET after $24 \mathrm{~h}$ of radiation with $900 \mathrm{MHz}$ radiation made by the mobile simulator. This difference in response to antibiotic sensitivity can result in the difference in the radiation frequency, the duration of radiation, the type of antibiotic and the structure of the bacteria. Adebayo et al. (2014) investigated the effect of radiofrequency radiations emitted from telecommunication base stations on the resistance of Bacillus bacteria, which increased the resistance of this bacterium [29]. This study, with our results, increased the resistance of both $S$. aureus and $P$. aeruginosa bacteria after $24 \mathrm{~h}$ exposure to $900 \mathrm{MHz}$ emitted waves from the mobile simulator.

Several studies have highlighted the causes of antimicrobial susceptibility changes of bacteria under the influence of electromagnetic fields [29-31]. A study showed that antimicrobial susceptibility depends on the physical properties of the magnetic field, such as frequency, duration of radiation, and the type of bacteria [32]. Another factor that can affect the antimicrobial susceptibility is the structure of the bacterial cell wall and the nature of the peptidoglycan properties in the cell wall of the gram-positive and negative bacteria [33].

Torgomyan et al. showed that changes in proteins in the bacterial cell wall could be the most important membrane mechanism for lowintensity electromagnetic field radiation [34].
Overall, studies in this area have described the following effective mechanisms: first, due to the importance of the membrane potential of the bacterial cell wall, these waves can have an effect on the antibiotic susceptibility [32]. Secondly, increased antibiotic susceptibility may be due to the interaction of electromagnetic fields on the water molecules in the cell. Other suggested mechanisms include increase in the permeability of the bacteria and makig the ion channels to be kept open in the bacterial wall, efflux pumps and ion channels in the cell wall, play an important role in the absorption of antibiotics, and finally, another factor that can affect bacterial sensitivity in magnetic conditions is the antibiotic structure [28, 35]. Hydrophilicity or hydrophobicity of the antibiotic, antibiotic activity and antibiotic molecule size are other factors [36].

\section{Conclusion}

In the present study, it has been shown that the waves emitted from the mobile simulator with a frequency of $900 \mathrm{MHz}$ can change the antimicrobial susceptibility of $S$. aureus and $P$. aeruginosa as a physical method. According to the obtained results, it can be concluded that the bacterial species used in this study were influenced by the electromagnetic field and responded differently.

\section{Acknowledgment}

We would like to acknowledge Shiraz University of Medical Sciences, for the generous funding of this work through grant No 94-0175-10643.

\section{Conflict of Interest}

None

\section{References}

1. Andersson DI. Persistence of antibiotic resistant bacteria. Curr Opin Microbiol. 2003;6:452-6. PubMed PMID: 14572536.

2. Meyer E, Jonas D, Schwab F, Rueden $H$, Gastmeier P, Daschner FD. Design of a surveillance system of antibiotic use and bacte- 
rial resistance in German intensive care units (SARI). Infection. 2003;31:208-15. PubMed PMID: 14562943.

3. Huang CR, Lu CH, Chuang YC, Tsai NW, Chang CC, Chen SF, et al. Adult Pseudomonas aeruginosa meningitis: high incidence of underlying medical and/or postneurosurgical conditions and high mortality rate. Jpn J Infect Dis. 2007;60:397-9. PubMed PMID: 18032844.

4. Jensen T, Pedersen SS, Garne S, Heilmann C, Hoiby N, Koch C. Colistin inhalation therapy in cystic fibrosis patients with chronic Pseudomonas aeruginosa lung infection. J Antimicrob Chemother. 1987;19:831-8. PubMed PMID: 3301785.

5. Mena KD, Gerba CP. Risk assessment of Pseudomonas aeruginosa in water. Rev Environ Contam Toxicol. 2009;201:71-115. doi: 10.1007/978-1-4419-0032-6_3. PubMed PMID: 19484589.

6. Bodey GP, Bolivar R, Fainstein V, Jadeja L. Infections caused by Pseudomonas aeruginosa. Rev Infect Dis. 1983;5:279-313. PubMed PMID: 6405475.

7. Lang AB, Furer E, Senyk G, Larrick JW, Cryz Jr SJ. Systematic generation of antigen specific human monoclonal antibodies with therapeutical activities using active immunization. Hum Antibodies Hybridomas. 1990;1:96-103. doi: 10.3233/hab-1990-1204. PubMed PMID: 2129420.

8. Merrer J, Santoli F, Appere De Vecchi C, Tran $\mathrm{B}$, De Jonghe B, Outin H. "Colonization pressure" and risk of acquisition of methicillinresistant Staphylococcus aureus in a medical intensive care unit. Infect Control Hosp Epidemiol. 2000;21:718-23. doi: 10.1086/501721. PubMed PMID: 11089656.

9. Haddadin AS, Fappiano SA, Lipsett PA. Methicillin resistant Staphylococcus aureus (MRSA) in the intensive care unit. Postgrad Med J. 2002;78:385-92. doi: 10.1136/ pmj.78.921.385.PubMed PMID: 12151652; PubMed PMCID: PMC1742438.

10.Le Loir Y, Baron F, Gautier M. Staphylococcus aureus and food poisoning. Genet Mol Res. 2003;2:63-76. PubMed PMID: 12917803.

11. Roy S, Santra S, Das A, Dixith S, Sinha M, Ghatak S, et al. Staphylococcus aureus Biofilm Infection Compromises Wound Healing by Causing Deficiencies in Granulation Tissue Collagen. Ann Surg. 2019. doi: 10.1097/ SLA.0000000000003053. PubMed PMID: 30614873.

12.Centers for Disease Control and Prevention (CDC). Staphylococcus aureus resistant to vancomycin--United States, 2002. MMWR Morb Mortal Wkly Rep. 2002;51:565-7. PubMed PMID: 12139181.

13.Tang J, Zhang Y, Yang L, Chen Q, Tan L, Zuo S, et al. Exposure to $900 \mathrm{MHz}$ electromagnetic fields activates the mkp-1/ERK pathway and causes blood-brain barrier damage and cognitive impairment in rats. Brain Res. 2015;1601:92-101. doi: 10.1016/j. brainres.2015.01.019.

14.Urbinello D, Joseph W, Verloock L, Martens $\mathrm{L}$, Roosli M. Temporal trends of radio-frequency electromagnetic field (RF-EMF) exposure in everyday environments across European cities. Environ Res. 2014;134:134-42. doi: 10.1016/j.envres.2014.07.003. PubMed PMID: 25127524.

15.Urbinello D, Joseph W, Huss A, Verloock L, Beekhuizen J, Vermeulen R, et al. Radiofrequency electromagnetic field (RF-EMF) exposure levels in different European outdoor urban environments in comparison with regulatory limits. Environ Int. 2014;68:49-54. doi: 10.1016/j.envint.2014.03.007. PubMed PMID: 24704639.

16. Repacholi MH. Low-level exposure to radiofrequency electromagnetic fields: health effects and research needs. Bioelectromagnetics. 1998;19:1-19. doi: 10.1002/(sici)1521186x(1998)19:1<1:aid-bem1>3.3.c0;2-8. PubMed PMID: 9453702.

17.Agarwal A, Desai NR, Makker K, Varghese A, Mouradi R, Sabanegh E, et al. Effects of radiofrequency electromagnetic waves (RFEMW) from cellular phones on human ejaculated semen: an in vitro pilot study. Fertil Steril. 2009;92:1318-25. doi: 10.1016/j.fertnstert.2008.08.022. PubMed PMID: 18804757.

18. McNamee JP, Chauhan V. Radiofrequency radiation and gene/protein expression: a review. Radiat Res. 2009;172:265-87. doi: 10.1667/ RR1726.1. PubMed PMID: 19708776.

19.Salehi I, Sani KG, Zamani A. Exposure of rats to extremely low-frequency electromagnetic fields (ELF-EMF) alters cytokines produc- 
tion. Electromagn Biol Med. 2013;32:1-8. doi: 10.3109/15368378.2012.692343. PubMed PMID: 23046051.

20. Moreau E. Airflow control by non-thermal plasma actuators. Journal of physics D: applied physics. 2007;40:605. doi: 10.1088/00223727/40/3/s01.

21. Preece A. Effect of a $915-\mathrm{MHz}$ simulated mobile phone signal on cognitive function in man. Int J Radiat Biol. 1999;75:447-56. doi: 10.1080/095530099140375.

22.Dogan $M$, Turtay $M^{*} G$, Oguzturk $H$, Samdanci E, Turkoz Y, Tasdemir S, et al. Effects of electromagnetic radiation produced by $3 G$ mobile phones on rat brains: magnetic resonance spectroscopy, biochemical, and histopathological evaluation. Hum Exp Toxicol. 2012;31:557-64. doi: 10.1177/0960327111412092. PubMed PMID: 21659345.

23.Fu TC. A Dual Communication and Imaging Underwater Acoustic System. University of California: Santa Barbara; 2011.

24.Lerner EJ. Biological effect of electromagnetic fields: New findings linking changes in organisms to irradiation by weak fields encourage researchers to posit theories, although research is incomplete. IEEE spectrum. 1984;21:57-69. doi: 10.1109/mspec.1984.6370269.

25. Krewski D, Glickman BW, Habash RW, Habbick B, Lotz WG, Mandeville R, et al. Recent advances in research on radiofrequency fields and health: 2001-2003. J Toxicol Environ Health B Crit Rev. 2007;10:287-318. doi: 10.1080/15287390600974973. PubMed PMID: 17620203.

26.Parajuli P, Panday JP, Koirala RP, Shah BR. Study of the Electromagnetic Field Radiated from the Cell Phone Towers Within Kathmandu Valley. International Journal of Applied Sciences and Biotechnology. 2015;3:179-87. doi: 10.3126/ijasbt.v3i2.12297.

27. Mortazavi SMJ, Darvish L, Abounajmi M, Zarei $S$, Zare $T$, Taheri $M$, et al. Alteration of Bacterial Antibiotic Sensitivity After ShortTerm Exposure to Diagnostic Ultrasound. Iran Red Crescent Med J. 2015;17:e26622. doi: 10.5812/ircmj.26622. PubMed PMID: 26732124; PubMed PMCID: PMC4698328.

28.Taheri M, Mortazavi SMJ, Moradi M, Mansouri
S, Hatam GR, Nouri F. Evaluation of the Effect of Radiofrequency Radiation Emitted From Wi-Fi Router and Mobile Phone Simulator on the Antibacterial Susceptibility of Pathogenic Bacteria Listeria monocytogenes and Escherichia coli. Dose Response. 2017;15:1-8. doi: 10.1177/1559325816688527. PubMed PMID: 28203122; PubMed Central PMCID: PMC5298474.

29.Adebayo E, Adeeyo A, Ayandele A, Omomowo I. Effect of radiofrequency radiation from telecommunication base stations on microbial diversity and antibiotic resistance. Journal of Applied Sciences and Environmental Management. 2014;18:669-74.

30.Crabtree DPE, Herrera BJ, Kang S. The response of human bacteria to static magnetic field and radiofrequency electromagnetic field. J Microbiol. 2017;55:809-15. doi: 10.1007/s12275-017-7208-7. PubMed PMID: 28956351.

31.Salmen SH, Alharbi SA, Faden AA, Wainwright $M$. Evaluation of effect of high frequency electromagnetic field on growth and antibiotic sensitivity of bacteria. Saudi $J$ Biol Sci. 2018;25:105-110. doi: 10.1016/j. sjbs.2017.07.006. PubMed PMID: 29379365; PubMed PMCID: PMC5775109.

32.Nguyen TH, Shamis $Y$, Croft RJ, Wood A, Mclntosh RL, Crawford RJ, et al. $18 \mathrm{GHz}$ electromagnetic field induces permeability of Gram-positive cocci. Sci Rep. 2015;5:10980. doi: 10.1038/srep10980. PubMed PMID: 26077933; PubMed PMCID: PMC4468521.

33.Belyaev I. Toxicity and SOS-response to ELF magnetic fields and nalidixic acid in $E$. coli cells. Mutat Res. 2011;722:56-61. doi: 10.1016/j.mrgentox.2011.03.012. PubMed PMID: 21497670.

34.Torgomyan $\mathrm{H}$, Tadevosyan $\mathrm{H}$, Trchounian A. Extremely high frequency electromagnetic irradiation in combination with antibiotics enhances antibacterial effects on Escherichia coli. Curr Microbiol. 2011;62:962-7. doi: 10.1007/s00284-010-9811-2. PubMed PMID: 21079961.

35.Taheri M, Mortazavi S, Moradi M, Mansouri S, Nouri F, Mortazavi S, et al. Klebsiella pneumonia, a microorganism that approves the non-linear responses to antibiotics and window theory after exposure to Wi-Fi $2.4 \mathrm{GHz}$ 
electromagnetic radiofrequency radiation. Journal of biomedical physics \& engineering. 2015;5:115.

36.Taheri M, Moradi M, Mortazavi S, Mansouri S, Hatam G, Nouri F. Evaluation of the 900
$\mathrm{MHz}$ Radiofrequency Radiation Effects on the Antimicrobial Susceptibility and Growth Rate of Klebsiella pneumoniae. Shiraz E-Medical Journal. 2017;18(3): e44946. doi: 10.17795/ semj44946. 